\title{
Effect of Grinding Time on the Particle Size Distribution Characteristics of Tuff Powder
}

\author{
Shuhua LIU $^{1 *}$, Hao WANG ${ }^{1}$, Hongling WANG ${ }^{1,2}$ \\ ${ }^{1}$ State Key Laboratory of Water Resources and Hydropower Engineering Science, Wuhan University, Wuhan 430072 , \\ China \\ ${ }^{2}$ Yellow River Engineering Consulting Co., Ltd, Zhengzhou 450003, China \\ crossref http://dx.doi.org/10.5755/j02.ms.23526
}

Received 04 June 2019; accepted 15 October 2019

\begin{abstract}
We study the grinding dynamic behavior and particle size distribution (PSD) characteristics of tuff powder. With the analysis of particle size and data of activity test, the results indicate that tuff powder is easy to be ground for the coarsegrained while is difficult for the fine-grained. It is feasible to quantitatively express the milling process of tuff powder by Divas-Aliavden milling dynamic equation. The milling speed and the milling time are negatively correlated, and the grinding efficiency is minimized after $60 \mathrm{~min}$. Equivalent particle size (EPS) is positively linearly correlated with the logarithm of grinding time, while specific surface area (SSA) is inversely correlated, both of them have a highly linear correlation. The PSD of tuff powder, which complies well with the Rosin-Rammler-Bennet (RRB) distribution model, has typical fractal characteristics, and its fractal dimension is also positively correlated with the milling time.

Keywords: tuff powder, particle size distribution characteristics, grinding kinetics, fractal characteristics.
\end{abstract}

\section{INTRODUCTION}

Tuff is a widely distributed inorganic non-metallic mineral resource [1], it contains a large amount of amorphous $\mathrm{SiO}_{2}$ and has a certain pozzolanic activity, which is similar to the most commonly used pozzolanic materials, such as fly ash [2]. Due to tight supply and expensive freight price of fly ash, several dam projects in remote areas of Western China have successfully used local tuff powder as mineral admixture in concrete [3].

Furthermore, theoretical study of tuff powder as aggregate of mineral admixture has also gradually increased in recent years. It was found that tuff fine aggregates can improve concrete strength, but its workability and durability are poor $[4,5]$. In addition to improving the mechanical properties of concrete, tuff aggregates can also reduce the bulk density per unit volume of concrete due to its lower density [6]. The mechanical properties of tuff mechanism sand concrete are better than the concrete with river sand, and their impermeability and crack resistance are basically equivalent $[7,8]$.

At present, the research on tuff powder mainly stays at the level of its macroscopic strength performance, but it has not yet touched the influence mechanism of tuff rock powder on the grinding dynamics of gelling system. At present, many scholars have studied the effects of grinding time and fineness on the performance of pozzolanic materials [8], such as fly ash, slag and glass powder, while these studies have never involved tuff powder.

Therefore, we mainly focus on the study of grinding dynamics of tuff powder, hoping to find a suitable equation to describe its dynamics of the milling process. In addition, we briefly discuss its fractal theory. We hope that this paper will be helpful to the practical application of tuff powder in engineering in the future.

\section{EXPERIMENTAL}

The tuff stone is purchased and transported from Fujian Province, China. After being cleaned, dried, crushed and sieved, the tuff sand with the original maximum size of $2.5 \mathrm{~mm}$ is ground by a $500 \mathrm{~cm}$ diameter nball mill. According to the milling time, we divide the tuff into five groups, which are A (10 min), B (30 min), C (60 min), D (90 $\mathrm{min}), \mathrm{E}(120 \mathrm{~min})$. The ball mill, with a total charge of $100 \mathrm{~kg}$ and a speed of $48 \mathrm{rpm}$, loads $5 \mathrm{~kg}$ sample. Meantime, there are four different size iron balls in the ball mill, whose number are $9(7 \mathrm{~cm}), 24(6 \mathrm{~cm}), 34(5 \mathrm{~cm})$ and $42(4 \mathrm{~cm})$.

The chemical compositions of tuff powder determined by X-ray fluorescence (XRF) are plotted in Table 1 . The main chemical components of tuff powder are $\mathrm{SiO}_{2}$ and $\mathrm{Al}_{2} \mathrm{O}_{3}$, which is similar to the pozzolanic materials. Furthermore, its total content of $\mathrm{SiO}_{2}, \mathrm{Al}_{2} \mathrm{O}_{3}$ and $\mathrm{Fe}_{2} \mathrm{O}_{3}$ is $82.63 \%$, meeting the regulation ( $\geq 70 \%$ ) of the ASTM C618-15 Standard Specification for the Content of Coal Fly Ash and Raw or Calcined Natural Pozzolan in Concrete.

In addition, the XRF we used is an Axios advanced Xray fluorescence spectrometer with a voltage of $30-60 \mathrm{kV}$ and a current of 50-100 mA. Utilizing Master Sizer 2000 (MS 2000), we also study the size distribution of tuff powder. At the same time, through the data handling, we have the equivalent particle size (EPS) and specific surface area (SSA).

\footnotetext{
* Corresponding author. Tel.: +86-27-68772233; fax: +86-27-68772310.

E-mail address: shliu@whu.edu.cn (S. Liu)
} 
Table 1. The chemical compositions of tuff powder, mass \%

\begin{tabular}{|c|c|c|c|c|c|c|c|c|c|c|c|c|c|}
\hline Compositions & $\mathrm{SiO}_{2}$ & $\mathrm{Al}_{2} \mathrm{O}_{3}$ & $\mathrm{CaO}$ & $\mathrm{Fe}_{2} \mathrm{O}_{3}$ & $\mathrm{FeO}$ & $\mathrm{MgO}$ & $\mathrm{Na}_{2} \mathrm{O}$ & $\mathrm{K}_{2} \mathrm{O}$ & $\mathrm{SO}_{3}$ & $\mathrm{TiO}_{2}$ & $\mathrm{MnO}_{2} \mathrm{P}_{2} \mathrm{O}_{5}$ & $\mathrm{Loss}$ \\
\hline Tuff powder & 72.35 & 14.25 & 1.01 & 1.20 & 1.75 & 0.71 & 2.85 & 4.43 & 0.13 & 0.38 & 0.09 & 0.09 & 0.71 \\
\hline
\end{tabular}

\section{RESULTS AND DISCUSSION}

\subsection{PSD of tuff powder}

In Fig. 1, we plot the particle size distribution curves of tuff powder at different milling time. It is clearly shown that the particle size of the tuff gradually diminishes as milling time increases.
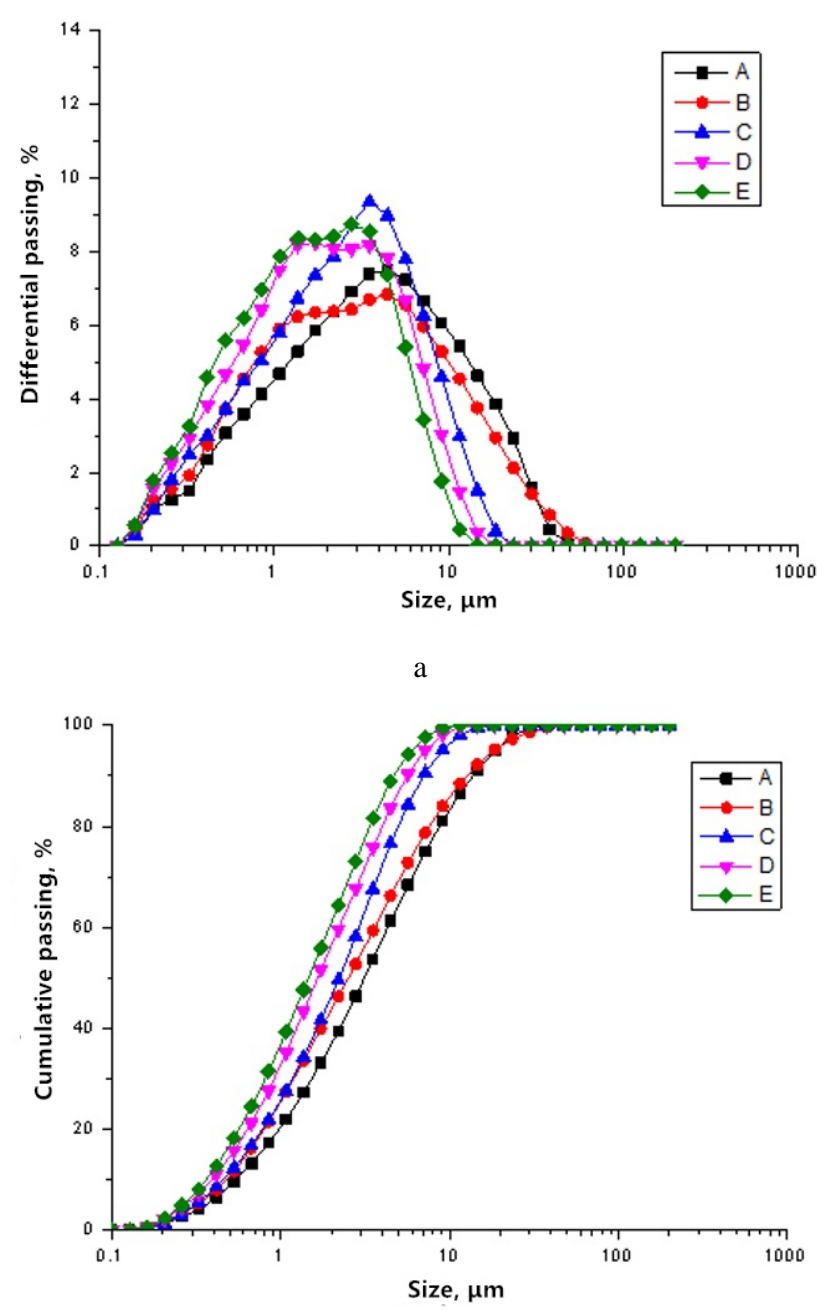

b

Fig. 1. PSD curves of tuff powder: a - differential curves; $\mathrm{b}$ - cumulative curves

\subsection{Grinding kinetic equation}

Divas and Fanrenwald have established a model that in the instant of grinding process $[9,10]$, the reduction rate of coarse particle content in certain diameter $(-d R / d t)$ is proportional to the coarse particle value $(R)$. The mathematical expression is shown as follows:

$\frac{d R}{d t}=-K_{t} R$,
Where, $R$ is the cumulative percentage of coarse particle content of a certain particle size after a certain grinding time; $t$ is the grinding time; $K_{t}$ is the milling speed constant. And Alivden Deng made some improvement as follows:

$$
R=R_{0} e^{-K_{t} t^{m}},
$$

Where, $R_{0}$ is the sieve residue of abrasive particles at a certain particle size at first; $m$ implies the time parameter, depending on ground material properties and its milling environment. As we identified $K_{t}$ and $m$, the grinding dynamic equation of the material at a certain particle size can be obtained.

According to the grinding dynamic equation and the experimental data of tuff powder, six representative particle diameters $(9.12 \mu \mathrm{m}, 5.67 \mu \mathrm{m}, 3.53 \mu \mathrm{m}, 2.19 \mu \mathrm{m}$, $1.08 \mu \mathrm{m}, 0.42 \mu \mathrm{m})$ are selected as the object. Experimental data of six representative particle size sieve residues are nonlinearly fitted according to the Eq. 2 as shown in Fig. 2. The parameters of the grinding dynamic equation corresponding to the six representative particle diameters are processed and shown in Table 2.

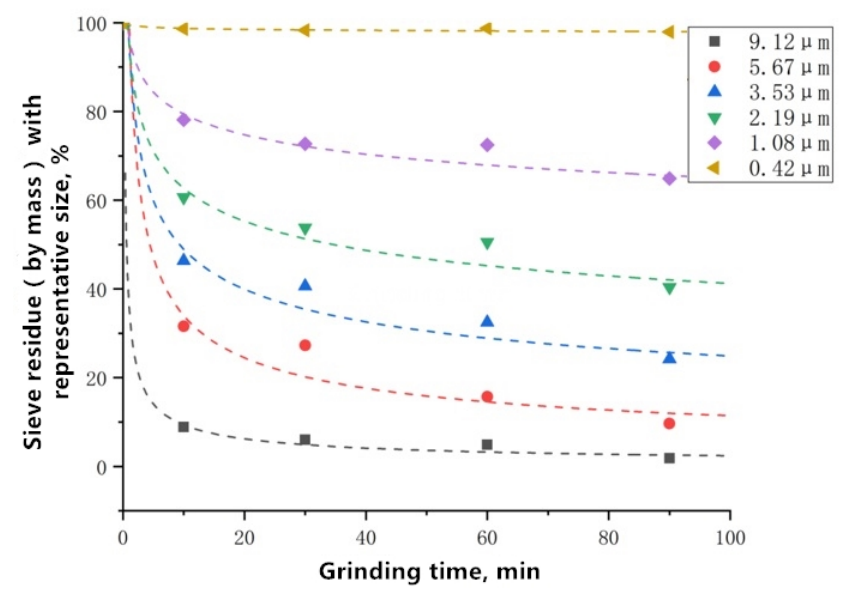

Fig. 2. The measured data and theoretical curves of tuff particle size with grinding time

From Fig. 2, we can see that the fitted curve has a high correlation coefficient, which indicates that the Alivden equation can represent the milling process nicely. As the grinding time increases, the sieve residues of each representative particle size are gradually reduced. The curves all glide with milling time, and tend to be convergent and stable after ground $60 \mathrm{~min}$. The larger the representative particle diameter, the greater the slope of the curve, which is consistent with the increase trend of $K_{t}$ in Table 2 and can be attributed that fine particles are more difficult to grind than coarse particles during the grinding process. On the whole, tuff powder is easy to be ground. After ground only $10 \mathrm{~min}$, the sieve residue percentage of the $9.12 \mu \mathrm{m}$ particle size is less than $10 \%$. It can be found that the value of $K_{t}$ decreases with the decrease of the representative particle size value while the value of $\mathrm{m}$ 
increases first and then decreases. The main reason for this phenomenon is likely to be that tuff powder is relatively easy to be ground finely, along with its grinding efficiency decreased over time and close to zero at $60 \mathrm{~min}$. Excessive grinding time cannot make obvious contribution to reduction of the particle size.

Table 2. Grinding kinetic parameters for six representative particle size

\begin{tabular}{|l|l|l|l|l|l|l|l|l|l|l|l|l|}
\hline Parameters & $9.12 \mu \mathrm{m}$ & $5.67 \mu \mathrm{m}$ & $3.53 \mu \mathrm{m}$ & $2.19 \mu \mathrm{m}$ & $1.08 \mu \mathrm{m}$ & $0.42 \mu \mathrm{m}$ \\
\hline
\end{tabular}

\begin{tabular}{|l|l|l|l|l|l|l|l|}
\hline$K_{t}$ & 1.4672 & 0.4978 & 0.2842 & 0.2396 & 0.1209 & 0.0077 \\
\hline
\end{tabular}

\begin{tabular}{l|l|l|l|l|l|l|l|}
\hline$m$ & 0.2068 & 0.3297 & 0.3751 & 0.2888 & 0.2802 & 0.2125 \\
\hline
\end{tabular}

According to the principle of crushing [11], in the initial grinding stage of tuff powder, the particles are large, and mainly crushed based on volume crushing, leading to a high grinding efficiency in early stage. As the particle size decreases, the tenacity of tuff powder increases, along with the volume pulverization gradually turns into the surface pulverization and small particles are agglomerated and formed "secondary particle", leading to a low grinding efficiency in the later stage. As a result, further development of crushing is blocked and grinding efficiency drops to near zero after excessive grinding time.

\subsection{EPS and SSA}

In this paper, EPS is short for equivalent particle size and refers to the particle diameter corresponding to the cumulative partial size distribution of the tuff powder reaching a certain percentage. For instance, D10 means the particle diameter when the cumulative particle size distribution percentage is $10 \%$. D50 is $50 \%$ of particles with a particle size smaller than it, while particles with a particle size larger than it also accounts for $50 \%$, so it is also called medium diameter, which is usually used to indicate the average particle size of powder. SSA is short for the specific surface area.

Table 3 shows the SSA and EPS of tuff powder ground for different time and cement, which displays that the EPS of tuff powder decreases while its SSA increases as the grinding time increases. After ground $10 \mathrm{~min}, \mathrm{D} 90$ and SSA of tuff powder are both close to those of cement, indicating that most particle size of tuff powder has been below $38.65 \mu \mathrm{m}$, drawing near to the fineness of cement. After ground $30 \mathrm{~min}$, the D90 of tuff powder is $12.71 \mu \mathrm{m}$, indicating that most particle size of tuff powder after grinding for $30 \mathrm{~min}$ is below $12.71 \mu \mathrm{m}$.

Utilizing the method of linear regression, we investigated the relationship between double logarithm of milling time with EPS and SSA of tuff powder to describe the grinding kinetics. The fitting curves, along with the fitting equations and the coefficient of correlation, are provided in Fig. 3 and Fig. 4. Both EPS and SSA have a good linear correlation with the double logarithm of milling time. In addition, the bigger the value of EPS is, the sharper it drops as milling time increases. Unlike coarse particles, fine particles are harder to grind, which coincidess with the grinding kinetics in section 3.2. Similarly, these fitting equations listed in Fig. 3 and Fig. 4 also present the grinding dynamic property.

Table 3. EPS and SSA of tuff powder

\begin{tabular}{|c|c|c|c|c|c|c|}
\hline Grinding time & $\mathrm{D} 10, \mu \mathrm{m}$ & $\mathrm{D} 25, \mu \mathrm{m}$ & $\mathrm{D} 50, \mu \mathrm{m}$ & $\mathrm{D} 75, \mu \mathrm{m}$ & $\mathrm{D} 90, \mu \mathrm{m}$ & $\mathrm{SSA}, \mathrm{m}^{2} / \mathrm{kg}$ \\
\hline $10 \mathrm{~min}$ & 1.18 & 2.63 & 5.25 & 13.36 & 38.65 & 371 \\
\hline $30 \mathrm{~min}$ & 0.48 & 0.98 & 2.52 & 6.21 & 12.71 & 590 \\
\hline $60 \mathrm{~min}$ & 0.46 & 0.97 & 2.23 & 4.30 & 7.05 & 805 \\
\hline $90 \mathrm{~min}$ & 0.39 & 0.77 & 1.66 & 3.44 & 5.61 & 907 \\
\hline $120 \mathrm{~min}$ & 0.36 & 0.68 & 1.46 & 2.94 & 4.68 & 950 \\
\hline Cement & 3.36 & 5.02 & 15.41 & 30.32 & 42.56 & 417 \\
\hline
\end{tabular}

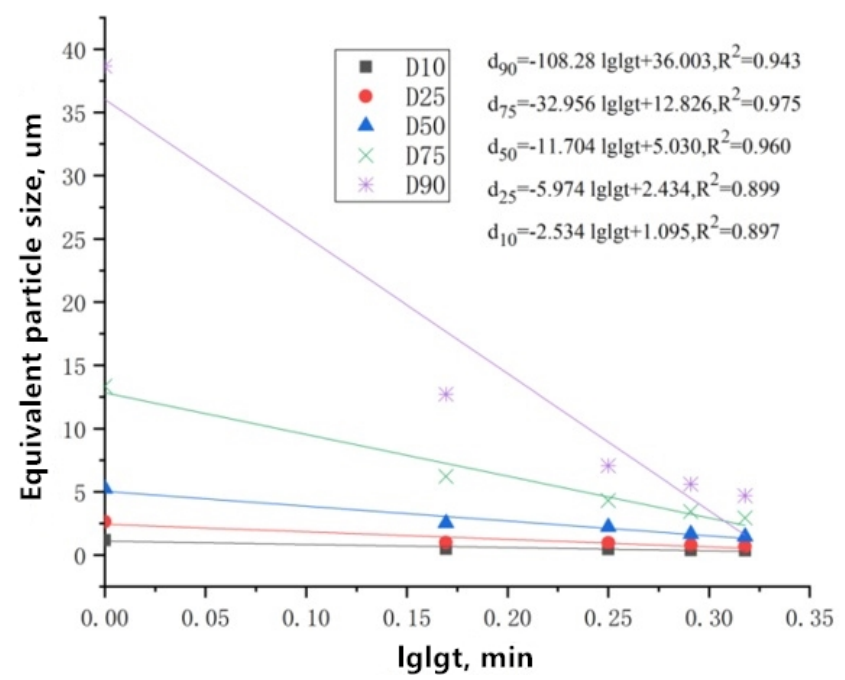

Fig. 3. Relationships between the EPS and double logarithm of milling time

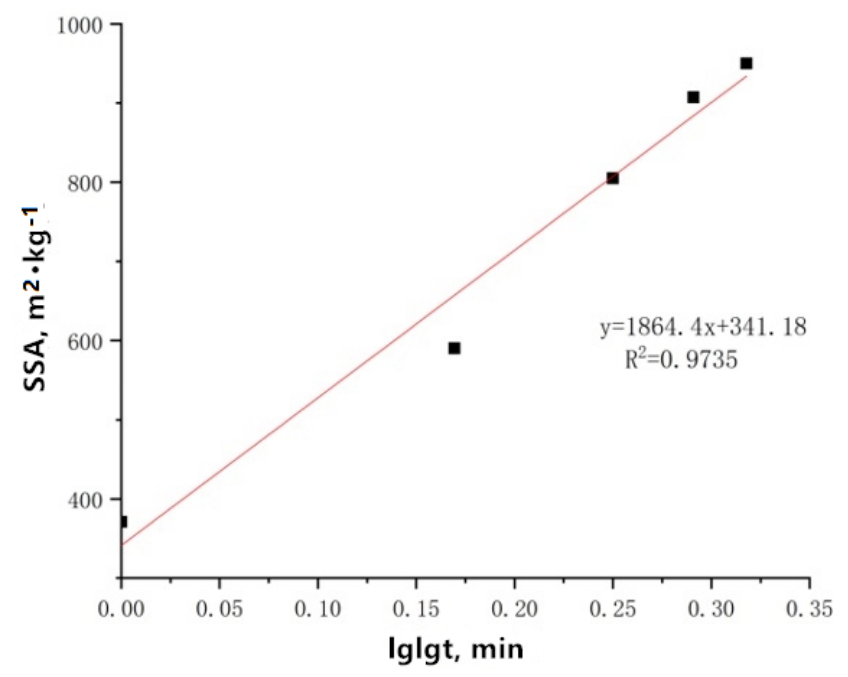

Fig. 4. Relationship between the SSA and double logarithm of milling time 


\subsection{PSD features}

PSD is short for particle size distribution. In addition to particle fineness, also the PSD features of the cementing material particle have an important influence on its hydration process and properties $[12,13]$. A systematic investigation on PSD features of tuff powder has a positive significance on characterizing tuff powder quantitatively, understanding the influence of tuff powder on cement hydration deeply and adjusting the grinding parameters.

There are researchers indicating that the PSD features of majority of cement systems are consistent with the RRB (Rosin-Rammler-Bennet) model, the formula of which is:

$$
R(x)=\exp \left[-\left(\frac{x}{x^{*}}\right)^{n}\right]
$$

Where, $R(x)$ is the mass fraction of the sieve while $x$ refers to the powder fineness; $x^{*}$ means the distribution feature size (the grain diameter as the sieve residue is $36.79 \%$ ), which reflects the size of majority of the powders in the system; n means the distribution index, representing the degree of centralization of system distribution. These two parameters can uniquely determine the distribution state of the powder. According to the laser particle size test data, the 5 samples (A, B, C, D, E) are nonlinearly fitted according to the RRB equation. Theoretical fitting curves and actual experimental data points are shown in Fig. 5. Each sample has a high degree of fitting. The PSD features of tuff powder are also in accordance with the RRB distribution model.

Corresponding parameters of RRB equation for tuff powder after different grinding times and cement are processed and listed in Table 4 . The feature size of tuff powder gradually reduces as grinding time increases, while the uniformity coefficient shows a downtrend first and then an uptrend later. After ground only 10 minutes, the feature size of tuff powder is $4.951 \mu \mathrm{m}$, which is far less than that of cement. However, after ground $90 \mathrm{~min}$, the uniformity coefficient of tuff powder almost close to cement. Before ground 60 minutes, the fineness of PSD increases and the particle distribution also becomes wider. Wide particle distribution may be beneficial for improving the PSD of cement-tuff powder composite cementitious system, increasing the bulk density of the powder system and abating the porosity of stiffened paste. After ground 60 min, the uniformity coefficient of tuff powder increases, which may be attribute to the agglomeration and forming "secondary particles", and lead to narrowing the PSD of tuff powder.

Table 4. Distribution coefficient and characteristic diameter of tuff powder and cement

\begin{tabular}{|c|c|c|c|c|c|c|}
\hline Samples & $\begin{array}{c}\mathrm{A} / 10 \\
\mathrm{~min}\end{array}$ & $\begin{array}{c}\mathrm{B} / 30 \\
\mathrm{~min}\end{array}$ & $\begin{array}{c}\mathrm{C} / 60 \\
\mathrm{~min}\end{array}$ & $\begin{array}{c}\mathrm{D} / 90 \\
\mathrm{~min}\end{array}$ & $\begin{array}{c}\mathrm{E} / 120 \\
\mathrm{~min}\end{array}$ & Cement \\
\hline$n$ & 0.938 & 0.901 & 0.897 & 1.091 & 1.161 & 1.087 \\
\hline$x^{*}$ (fitted) & 4.951 & 4.187 & 3.156 & 2.463 & 2.125 & 16.375 \\
\hline $\begin{array}{c}x^{*} \\
\text { (measured) }\end{array}$ & 4.738 & 4.170 & 3.294 & 2.459 & 2.279 & 18.665 \\
\hline
\end{tabular}

\subsection{Fractal features of PSD}

In recent years, fractal theory extends our thought on particle size analysis. The fractal model presumes a certain amount of material has certain regularity, such as similar chance and size, when it is decomposed into granule, and the procedure from meso-damgae to macro-fracture showing self-similar behavior and fractal features. When the process is repeated indefinitely in the milling or crushing process, we will have particles with a fractal property distribution. As a brittle material, the PSD of tuff powder also meets the fractal model characteristics, which has a high degree of matching with Griffith's model [14]. In Griffith's model, fractal dimension (D) is the parameter to represent fractal features, which can be calculated as follows [15]:

$$
D=3-b \text {, }
$$

Where, $b$ is the slope of $\lg \left(m_{c} / m\right)-\lg c$ curve; $m_{c} / c$ means the cumulative content of particles smaller than $c$ (by mass \%).

From Fig. 6, we can see the $\lg \left(m_{c} / m\right)-\lg c$ curves calculated by the experimental data.

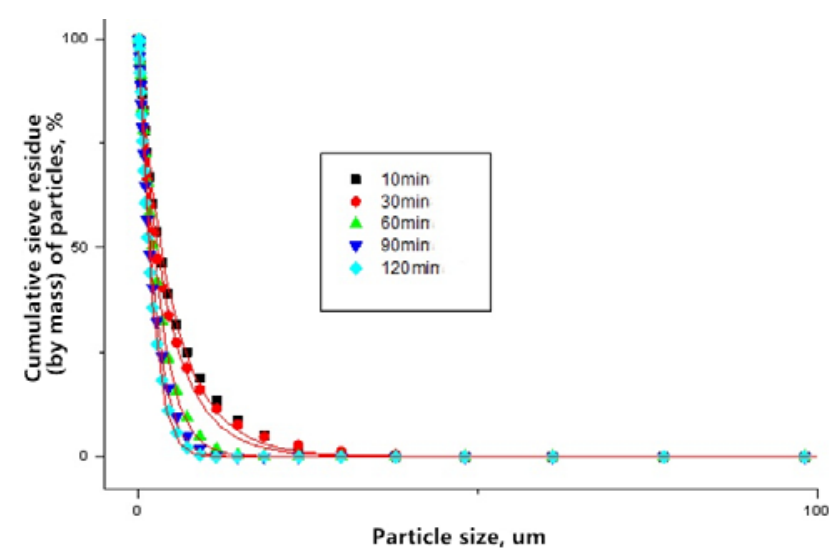

Fig. 5. Measured data and theoretical curve of PSD of tuff powder

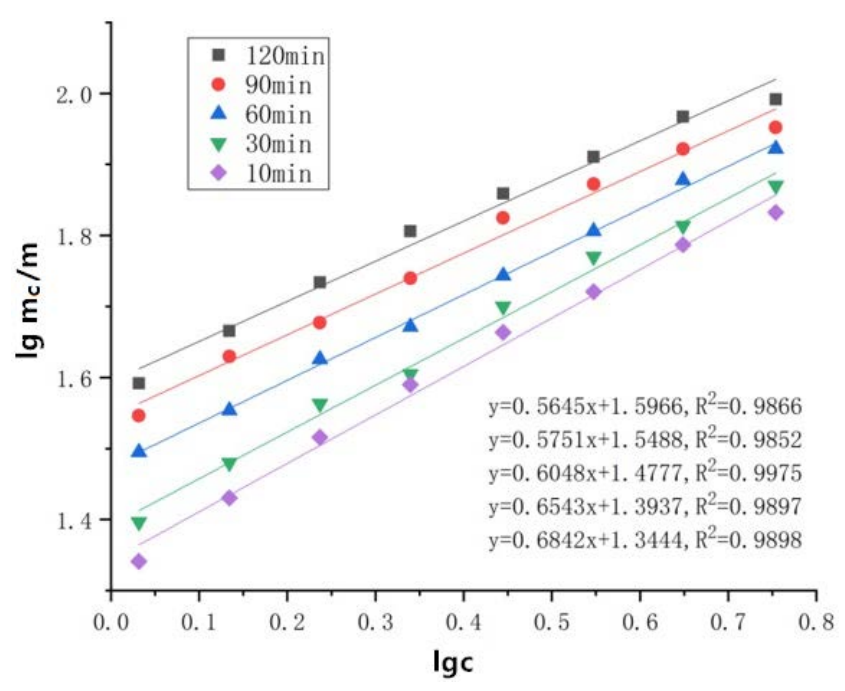

Fig. 6. $\lg \left(m_{c} / m\right)-\lg c$ curves

The 5 samples show a high degree of linear fitting, with all coefficients $\mathrm{R}^{2}$ are higher than 0.985 , which indicates that the PSD of tuff powder has typical fractal characteristic. Furthermore, as shown in Table 5, the fractal dimension of PSD increases gradually as the milling time increases, and the tuff powder is difficult to be finely ground with the increase of the fractal dimension of PSD. 
Table 5. Fractal dimension of PSD of tuff powder

\begin{tabular}{|c|c|c|c|c|c|}
\hline Grinding time & $10 \mathrm{~min}$ & $30 \mathrm{~min}$ & $60 \mathrm{~min}$ & $90 \mathrm{~min}$ & $120 \mathrm{~min}$ \\
\hline$D$ & 2.316 & 2.356 & 2.395 & 2.425 & 2.435 \\
\hline
\end{tabular}

\section{CONCLUSIONS}

1. Tuff powder is easy to be ground finely. After ground only $10 \mathrm{~min}$, the sieve residue percentage of the $9.12 \mu \mathrm{m}$ particle size is less than $10 \%$. Tuff powder is easy to be ground for the coarse-grained while is difficult for the fine-grained.

2. It is feasible to quantitatively express the milling process of tuff powder by Divas-Aliavden milling dynamic equation. The milling efficiency of tuff powder declines over milling time and drops to the lowest value (almost zero) after $60 \mathrm{~min}$, excessive milling time cannot make obvious contribution to reduction of the particle size.

3. As the grinding time increases, EPS of tuff powder becomes smaller gradually while SSA increases. Both the EPS and the SSA of tuff powder have highly linear correlativity with double logarithm of milling time.

4. Similar to cement, the RRB model is also suitable for quantitative description of the PSD features of tuff powder. After ground $10 \mathrm{~min}$, the PSD of tuff powder is much less than that of cement. During the first hour of grinding, not only the fineness of tuff powder increases, but also its particle distribution is widening. After ground $60 \mathrm{~min}$, the uniformity coefficient of tuff powder increases, resulting in a narrow distribution of the PSD of tuff powder.

5. The PSD of tuff powder has typical fractal characteristics, and its fractal dimension $\mathrm{D}$ rises as the milling time increases. Tuff powder is difficult to be ground finely with the increased of the fractal dimension of PSD.

\section{Acknowledgments}

This project is funded by the National Key R\&D Program of China (2018YFC1801704).

\section{REFERENCES}

1. Mu, S.C. Physical and Chemical Features of Tuff and Its Development and Application Non-metallic Mines 3 2000: pp. $17-20$. https://doi.org/10.3969/j.issn.1004-4051.2000.03.005

2. Ababneh, A., Matalkah, F. Potential Use of Jordanian Volcanic Tuffs as Supplementary Cementitious Materials Case Studies in Construction Materials 8 2018: pp. 193-202. https://doi.org/10.1016/j.cscm.2018.02.004

3. Peng, S. Study of the Key Technologies of Application of Tuff Powder Concrete at the Daigo Hydropower Station in Tibet Construction \& Building Materials 156 2017: pp. $1-8$. https://doi.org/10.1016/j.conbuildmat.2017.08.138

4. Cherrak, M., Bali, A., Silhadi, K. Corrigendum to "Concrete Mix Design Containing Calcareous Tuffs as a Partial Sand Substitution" Construction \& Building Materials 81 2015: pp. 324-324.

https://doi.org/10.1016/j.conbuildmat.2015.02.017

5. Yasin, A.A., Awwad, M.T., Hajjeh, H.R. Effect of Volcanic Tuff on the Concrete Compressive Strength Contemporary Engineering Sciences 12 2012: pp. $72-76$. http://dx.doi.org/10.12988/ces.2012.3736

6. Al-Zou'by, J., Al-Zboon, K.K. Effect of Volcanic Tuff on the Characteristics of Cement Mortar Cerâmica 60 2014: pp. 279-284. https://doi.org/10.1080/19648189.2015.1053151

7. Zhou, Y., Chen, S. Research on the Mechanical and Durability Performance of Tuff Manufactured Sand Concrete Used for Box Girder Construction Technology 44 2015: pp. $16-18$. https://doi.org/10.7672/sgjs2015180016

8. Li, Z., Zhou, Y. Experimental Study of Tuff Manufactured Sand on Chloride Resistance of Marine Concrete Bulletin of the Chinese Ceramic Society 34 2015: pp. 955-959. https://doi.org/10.16552/j.cnki.issn1001-1625.2015.04.012

9. Kano, J., Miyazaki, M., Saito, F. Ball Mill Simulation and Powder Characteristics of Ground Talc in Various Types of Mill Advances in Powder Technology 11 (3) 2000: pp. 333-342. https://doi.org/10.1163/156855200750172204

10. Kotake, N., Suzuki, K., Asahi, S. Experimental Study on the Grinding Rate Constant of Solid Materials in a Ball Mill Powder Technology 122 (2-3) 2002: pp. 101-108. https://doi.org/10.1016/S0032-5910(01)00405-3

11. Pan, R., Huang, $\mathbf{H}$., Shen, $\mathbf{X}$. Effect of Grinding Time on Particle Properties of Mineral Admixtures Concrete 2 2007: pp. 55-60. https://doi.org/10.3969/j.issn.1002-3550.2007.02.017

12. Basim, G.B., Khalili, M. Particle Size Analysis on Wide Size Distribution Powders: Effect of Sampling and Characterization Technique Advances in Powder Technology 26 (1) 2014: pp. 200-207. https://doi.org/10.1016/j.apt.2014.09.009

13. He, T., Zhao, X., Zhao, S. Fractal Characteristics of Converter Steel-Slag Particle Size Distribution Bulletin of the Chinese Ceramic Society 34 (11) 2013: pp. 2346-2351. https://doi.org/10.16552/j.cnki.issn1001-1625.2013.11.017

14. Wei, H., Zhang, Y.S., Li, T.R. Relationship between Fractal Features of Microvoid Grains Distribution and Strength of Rock Chinese Journal of Rock Mechanics and Engineering 19 (3) 2000: pp. 318-320. https://doi.org/10.3321/j.issn:1000-6915.2000.03.013

15. Yu, K., Zheng, Z. Fractal Study on Granularity Distribution of Powder Materials Science \& Engineering 13 (3) 1995: pp. 30-34.

https://doi.org/10.14136/j.cnki.issn1673-2812.1995.03.006 